\title{
PENGARUH PENEMPATAN PENGHALANG BERBENTUK SEGITIGA DI DEPAN SILINDER DENGAN VARIASI KECEPATAN ALIRAN UDARA TERHADAP KOEFISIEN DRAG
}

\author{
Si Putu Gede Gunawan Tista, I Gusti Agung Kade Suriadi, Putu Pageh Astawa \\ Jurusan Teknik Mesin, Fakultas Teknik, Universitas Udayana \\ E-mail: Gunawan_tista@yahoo.com
}

\begin{abstract}
One of the ways to preserve energy on the air plane is by decreasing the drag. Drag is closely related to the flow separation, the faster the separation, then the drag will increase more. Because of that, efforts were conducted to decrease drag is by manipulating a fluid flow field that is by installing triangle rod obstacle in front of the cylinder. The purpose of this research is to analyze the effect of installing triangle rod obstacle in front of the cylinder by various air flow velocity on the drag cofficient. In this research, the experiment was conducted in the wind tunnel, which consists of blower, pitot pipe, manometer, cylinder pipe, and triangle rod. The air flow velocity was varied from $6.25 \mathrm{~m} / \mathrm{s}, 5.01 \mathrm{~m} / \mathrm{s}, 4.09 \mathrm{~m} / \mathrm{s}, 3.17 \mathrm{~m} / \mathrm{s}, 2.24 \mathrm{~m} / \mathrm{s}$. The Reynold number based on cylinder $(D=42 \mathrm{~mm})$ and air flow velocity is $R e=18.100,14.500$, $11.800,9.170,6.480$. The distance triangle rod and cylinder is $L=70 \mathrm{~mm}$ or $L / D=1.67$. Pressure distribution is achieved by measuring the cylinder surface on 36 spots with interval of $10^{\circ}$. The measured data was pressure of cylinder surface, static pressure, and airflow speed. The research results showed that the triangle rod could decrease the drag of cylinder. Coefficient drag for cylinder without triangle rod was 0,1276 while the less triangle rod was 0,01882 which takes place at speed $6,2479 \mathrm{~m} / \mathrm{s}$.
\end{abstract}

Keywords: Triangle rod, air flow velocity, drag coefficient

\section{PENDAHULUAN}

Gerakan aliran fluida melintasi suatu benda (bluff body) memegang peranan penting dalam aplikasi enginering seperti pada penukar kalor, pembakaran dan alat transportasi. Dengan demikian penelitian fenomena aliran tersebut menjadi sangat penting jika dikaitkan dengan krisis energi yang melanda dunia dewasa ini.

Aliran eksternal viscous yang mengalir melalui silinder akan mengalami stagnasi, lapisan batas, separasi (pemisahan) dan wake di belakang silinder. Untuk benda yang bergerak dalam fluida viscous, gaya drag (gaya hambat) and gaya lift (gaya angkat) erat hubungannya dengan separasi aliran (Chew et al., 1997).

Adanya separasi aliran akan menyebabkan timbulnya wake di belakang silinder yang mengakibatkan drag (hambatan). Semakin cepat terjadinya separasi aliran, wake akan semakin lebar sehingga drag semakin besar.
Dalam dunia transportasi seperti pesawat udara, mobil atau kapal laut, drag yang besar dihindari, karena energi atau tenaga yang dibutuhkan untuk bergerak menjadi lebih besar. Berbagai upaya telah dilakukan untuk mengurangi drag, diantaranya dengan membuat body yang streamline atau memanipulasi medan aliran. Sebagai contoh, jika drag dari mobil dan bangunan dapat dikurangi maka banyak biaya bahan bakar danm material yang dapat dihemat (Tsutsui dan Igarasi, 2002).

Dalam apliaksi teknik, banyak sekali konstruksi yang menggunakan silinder, hal ini telah mendorong banyak peneliti untuk melakukan penelitian tentang aliran melintasi silinder. Oleh karenanya, sampai saat ini penelitian aliran melintasi silinder tetap sebagai salah satu yang penting dalam mekanika fluida (Bouk et al., 1998). Sehingga, penting untuk melakukan studi dengan silinder sebagai obyek. Tujuan dari penelitian ini adalah menganalisa pengaruh penempatan penghalang berbentuk segitiga di depan 
silinder dengan variasi kecepatan aliran udara terhadap koefisien drag.

Berbagai penelitian tentang drag yang mendukung penelitian ini antara lain :

Lee, et al. (2004), meneliti pengaruh pemasangan batang kontrol kecil pada upstream dari silinder dengan fokus pada karakteristik drag. dan struktur aliran. Bilangan Reynold berdasarkan silinder utama $(D=30$ $\mathrm{mm}$ ) adalah sekitar $\operatorname{Re}=20000$. Maksimum pengurangan koefisien total drag dari seluruh sistem meliputi silinder utama dan batang kontrol sekitar $25 \%$.

Tsutsui \& Igarashi (2002), mengkaji aliran sekitar silinder dengan menempatkan batang kecil pada upstream dari silinder. Diameter silinder adalah $D=40 \mathrm{~mm}$, dan diameter batang d rentangnya dari 1 sampai $10 \mathrm{~mm}$.. Angka Reynold didasarkan pada D rentang dari $1,5 \times 10^{4}$ sampai $6,2 \times 10^{4}$. Pengurangan total drag yang meliputi drag dari batang adalah $63 \%$ dibandingkan dengan yang satu silinder.

Igarashi (1997), Mengkaji aliran sekitar Prisma segiempat dengan menempatkan batang kecil di depan prisma (upstream). Panjang sisi prisma $D$ adalah $30 \mathrm{~mm}$ dan bilangan Reynold $\operatorname{Re}$ adalah $3,2 \times 10^{4}$. Pada jarak kritis $G_{c}=D+4,5 d$, vortex dari batang hilang. Drag dari prisma menurun sekitar $50 \%$ pada $G>G_{c}$ dan $70 \%$ pada $G \leq G_{c}$.

Yajima \& Sano (1996), Mengkaji aliran sekitar silinder dengan melubangi sepanjang silinder dalam dua baris yang dibuat melintang diamater silinder. Pengurangan drag luar biasa didapat untuk bermacam-macam sudut serang. Besarnya pengurangan drag adalah $40 \%$ dibandingkan dengan silinder halus.

Sutardi \& Ching (1999), mengkaji pertumbuhan lapisan batas turbulen di belakang sebuah alur melintang yang berpenampang bujur sangkar. Dari hasil kajian ini diperoleh hasil bahwa ada suatu lonjakan tegangan geser pada lokasi sedikit di belakang alur melintang. Di belakang lonjakan tegangan geser itu kemudian disusul dengan penurunan tegangan geser yang lebih rendah dari nilai pada kasus permukaan halus (tanpa alur). Selanjutnya, tegangan geser itu kembali seperti halnya pada permukaan halus. Dari hasil integrasi tegangan geser pada dinding ( $\tau_{w}$ ) sepanjang permukaan uji, diperoleh hasil bahwa terjadi kenaikan gaya seret sebesar \pm $1 \%$ untuk kasus lapis batas turbulen dengan $R_{\theta}=1000$. Untuk kasus $R_{\theta}=3000$, integrasi tersebut menunjukkan bahwa gaya seret yang terjadi pada permukaan yang beralur sama besar dengan gaya seret yang terjadi pada permukaan halus.

Bouk, at al. (1998), melakukan studi eksperimental menggunakan silinder kecil sebagai pengontrol pasif untuk mengurangi gaya drag pada silinder utama. Hasil eksperimental mereka menunjukkan bahwa rata-rata penurunan gaya hambat maksimum sekitar $48 \%$ relatif terhadap silinder tunggal (tanpa pengontrol pasif).

\section{TINJAUAN PUSTAKA}

Aliran inkompresibel melintasi silinder dapat dilihat pada Gambar 1.

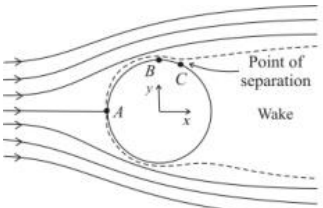

(a) Aliran Viscous

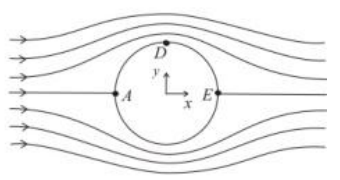

(b) Aliran inviscid
Gambar 1. Gambar Kualititatif aliran pada suatu silinder (Fox, 1985)

Pada Gambar1.a. menunjukkan aliran viscous pada suatu silinder, streamlines adalah simetris. Titik $A$ adalah titik stagnasi dan selanjutnya terjadi boundary layer. Dari titik A ke titik B terjadi kenaikan kecepatan yang berakibat penurunan tekanan dan selanjutnya dari titik $B$ ke titik $C$ terjadi penurunan kecepatan yang berarti terjadi kenaikan tekanan PC $>$ PB. Di titik C momentum aliran tidak mampu melawan tegangan geser sehingga menyebabkan pecahnya boundary layer. Titik C disebut dengan point of separation. Di antara titik-titik atau tempat-tempat pemisahan boundary layer terjadi suatu kawasan yang disebut dengan wake. Makin besar wake makin besar terjadi perbedaan gaya di depan dan di belakang silinder berakibat makin besar gaya seret aliran terhadap silinder. Aliran inviscid diGambarkan pada Gambar 1.b. terlihat bahwa streamlines simetris, terjadi slip pada permukaan silinder dan perbedaan besar kecilnya kecepatan aliran ditunjukkan oleh 
rapat longgarnya streamlines yang ada dan dengan: juga tidak terjadi wake sehingga tidak terjadi gaya seret pada silinder.

Pengaruh turbulensi pada separasi aliran yang melintasi silinder dapat dilihat pada Gambar 2.

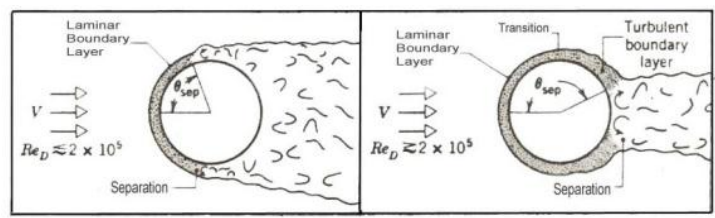

Gambar 2. Pengaruh turbulensi pada separasi (Incropera \& DeWitt, 1981).

Karena momentum fluida dalam lapisan batas turbulen lebih besar dari pada lapisan batas laminer, maka kemampuannya untuk melawan tegangan geser lebih besar sehingga akan lebih mampu untuk menunda yang menyebabkan separasi, itu layak untuk mengharapkan transisi. Jika $R_{D} \leq 2 \times 10^{5}$, lapisan batas tetap laminer, dan separasi terjadi pada $\theta \approx 80^{\circ}$. Tetapi, jika $\operatorname{Re}_{D} \geq 2 \times 10^{5}$, terjadi transisi lapisan batas, dan separasi ditunda sampai $\theta \approx 140^{\circ}$.

Pada penelitian ini perhitungan koefisien tekanan digunakan persamaaan (Lee, et al., 2004):

$$
C_{P}=\frac{P-P_{o}}{\frac{1}{2} \rho U_{o}^{2}}
$$

$$
\begin{aligned}
& P=\text { Tekanan permukaan }\left(\mathrm{N} / \mathrm{m}^{2}\right) \\
& P_{o}=\text { Tekanan statik }\left(\mathrm{N} / \mathrm{m}^{2}\right) \\
& U_{0}=\text { Kecepatan aliran bebas }(\mathrm{m} / \mathrm{s}) \\
& \rho=\text { Densitas udara }\left(\mathrm{kg} / \mathrm{m}^{3}\right)
\end{aligned}
$$

Koefisien drag yang bekerja pada silinder utama diperoleh dengan mengintegralkan tekanan permukaan pada silinder (Lee, et al., 2004) :

$$
C_{D}=\int \frac{\left(P-P_{o}\right) d A}{1 / 2 \rho U_{o}^{2} D C}
$$

dengan :

$$
\begin{array}{ll}
\mathrm{P} & =\text { Tekanan permukaan silinder }\left(\mathrm{N} / \mathrm{m}^{2}\right) \\
\mathrm{P}_{\mathrm{o}} & =\text { Tekanan statis }\left(\mathrm{N} / \mathrm{m}^{2}\right) \\
\mathrm{C} & =\text { Panjang silinder }(\mathrm{m}) \\
\mathrm{D} & =\text { Diameter silinder }(\mathrm{m}) \\
\mathrm{U}_{0} & =\text { Kecepatan aliran bebas }(\mathrm{m} / \mathrm{s}) \\
\rho & =\text { densitas udara }\left(\mathrm{kg} / \mathrm{m}^{3}\right)
\end{array}
$$

\section{METODOLOGI PENELITIAN}

Peralatan yang digunakan dalam penelitian ini adalah lorong udara (wind tunnel), pipa pitot, manometer, silinder utama, silinder penghalang, dan blower. Adapun susunan alat uji adalah seperti pada Gambar 3.
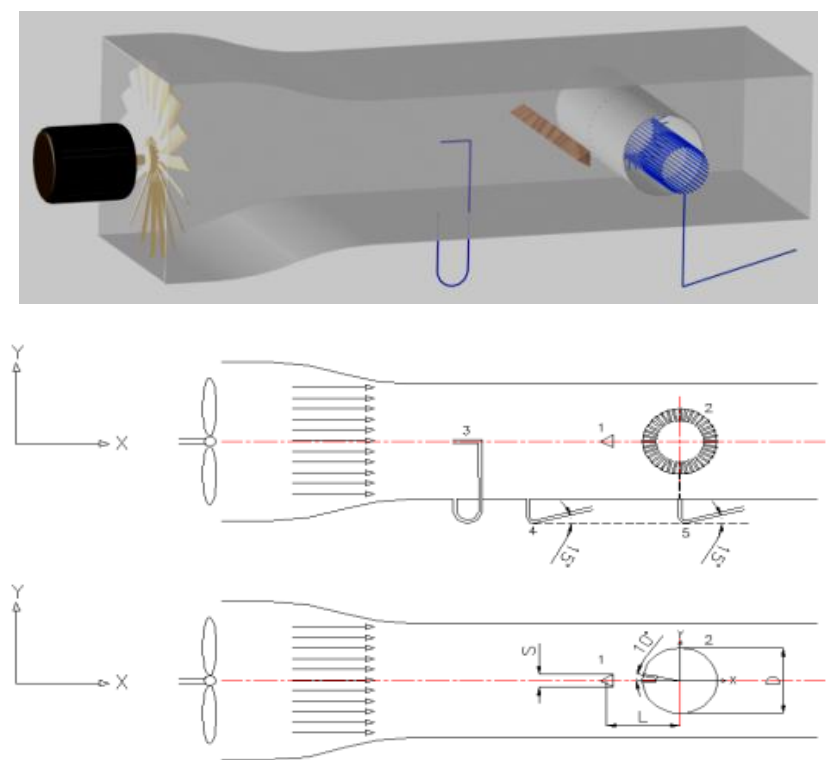

Gambar 3.Skema instalasi penelitian 
Cara Kerja Dan Teknik Pengambilan Data

Aliran udara yang dihembuskan oleh blower mengalir dalam wind tunnel dan melintasi penghalang berbentuk segitiga sama sisi dan mengenai silinder. Silinder yang digunakan pipa PVC jenis AW, Permukaan silinder dilubangi sebanyak 36 lubang dengan diameter $1 \mathrm{~mm}$, dan dihubungkan dengan selang berdiameter $2 \mathrm{~mm}$ ke inclined manometer. Pemasangan pressure tube dilakukan pada keliling silinder pada bagian tengah. Posisi tiap titik dari pressure tube berjarak $10^{\circ}$ dari titik pusat, sehingga akan diperoleh 36 titik pressure tube pada silinder.

Untuk mengukur tekanan permukaan $(P)$ (alat ukur 5), pembacaan manometer dilakukan secara manual. Kecepatan aliran udara wind tunnel diukur dengan pipa pitot (3) yang membaca tekanan total, sedangkan alat ukur (4) yang dihubungkan dengan selang berdiameter $2 \mathrm{~mm}$ untuk mengukur tekanan statis (Po) yang juga dibaca secara manual. Kecepatan udara bebas Uo diproses dari tekanan dinamik yakni selisih antara tekanan total dan tekanan statik.

\section{HASIL DAN PEMBAHASAN Pembahasan Grafik}

Hasil penelitian dengan varisi kecepatan aliran udara udara $\mathrm{U}_{0}=6.2479 \mathrm{~m} / \mathrm{s}, 5.0051$ $\mathrm{m} / \mathrm{s}, 4.0862 \mathrm{~m} / \mathrm{s}, 3.1651 \mathrm{~m} / \mathrm{s}, 2.2383 \mathrm{~m} / \mathrm{s}$, dengan bilangan Reynold masing-masing $\mathrm{Re}=$ $18.100,14.500,11.800,9.170,6.480$ adalah seperti terlihat pada Gambar 4. Pada Gambar 4. menunjukkan hubungan koefisien tekanan $(\mathrm{Cp})$ terhadap sudut silinder $(\theta)$, dengan tanpa penghalang dan penghalang, pada kecepatan aliran udara masing-masing $6.25 \mathrm{~m} / \mathrm{s}, 5.01 \mathrm{~m} / \mathrm{s}$, $4.09 \mathrm{~m} / \mathrm{s}, 3.17 \mathrm{~m} / \mathrm{s}, 2.24 \mathrm{~m} / \mathrm{s}$ atau pada bilangan Reynold $\mathrm{Re}=18.100,14.500$, 11.800, 9.170, dan 6.480.Terlihat terjadi penurunan tekanan yang lebih tajam dibandingkan dengan tanpa penghalang, tekanan stagnasi tidak lagi pada sumbu silinder tetapi sudah bergeser sesuai dengan besarnya segitiga penghalang.Titik separasi juga berubah antara dengan penghalang dan tanpa penghalang sesuai dengan kecepatan aliran udara. Pada tanpa penghalang separasi terjadi kira-kira pada sudut $110^{\circ}$ sedangkan dengan penghalang pada $R e=18.100$ dan $R e=14.500$ separasi bisa ditunda, terjadi pada sudut $120^{\circ}$ sampai $130^{\circ}$, sedangkan pada $R e$
$=11.800, \operatorname{Re}=9.170$ dan $\operatorname{Re}=6.480$

separasi terjadi pada sudut $100^{\circ}$. Hal ini disebabkan pada $\operatorname{Re}=11.800, \operatorname{Re}=9.170$ dan $\mathrm{Re}=6.480$ momentum aliran kurang untuk mengatasi gesekan sehingga separasi tidak bisa ditunda.

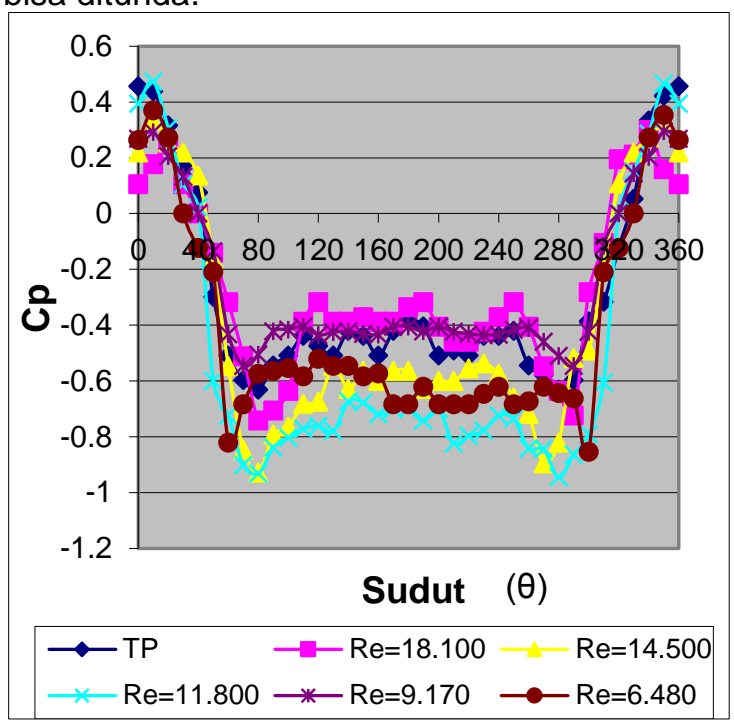

Gambar 4. Grafik Hubungan antara Koefisien Tekanan Cp terhadap sudut silinder $(\theta)$ dengan Variasi kecepatan aliran udara.

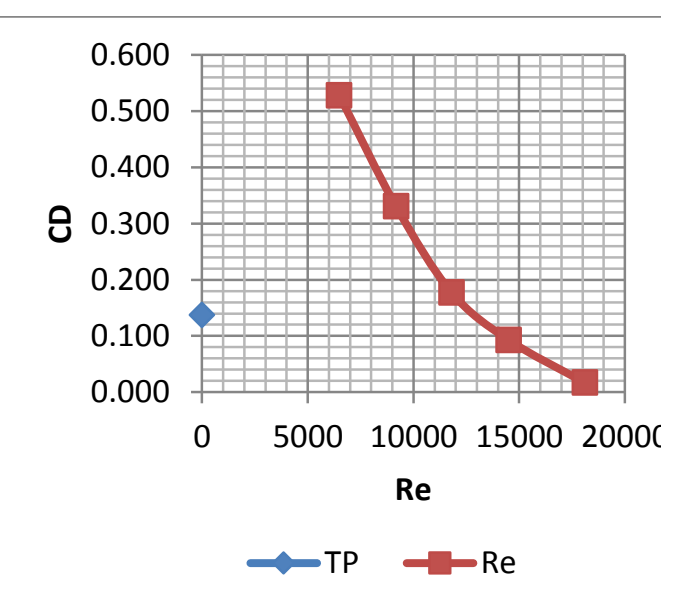

Gambar 5. Grafik Hubungan antara Koefisien Drag $(\mathrm{CD})$ terhadap Bilangan Reynold $(\mathrm{Re})$

Pada Gambar 5. Menunjukkan hubungan koefisien drag (CD) terhadap bilangan Reynold $(R e)$ dengan penghalang dan tanpa penghalang. Terlihat bahwa semakin besar bilangan Reynold koefisien drag semakin kecil. 
Hal ini disebabkan pada bilangan Reynold yang lebih besar atau pada kecepatan aliran yang lebih besar, momentum aliran lebih mampu untuk mengatasi tegangan geser yang terjadi, sehingga separasi terjadi jauh dibelakang silinder dan menyebabkan wake dibelakang silinder menjadi lebih sempit. Pada bilangan Reynold yang lebih rendah yaitu $R e=$ 11.800, $\operatorname{Re}=9.170$ dan $\operatorname{Re}=6.480$ koefisien drag yang terjadi besar bahkan lebih besar disbanding tanpa penghalang. $\mathrm{Hal}$ ini disebabkan pada bilangan Reynold yang lebih rendah atau kecepatan yang lebih rendah momentum aliran lebih rendah sehingga tidak mampu mengatasi tegangan geser yang terjadi ketika melintasi silinder. Oleh karena itu, separasi yang terjdi pada saat melintasi silinder tidak bisa dtunda sehingga menyebabkan wake dibelakang silinder menjadi lebih lebar.Koefisien drag terendah terjadi pada bilangan Reynold $\mathrm{Re}=18.100$ atau pada kecepatan aliran $6.25 \mathrm{~m} / \mathrm{s}$ yaitu sebesar 0.01695. Besarnya penurunan koefisien drag pada kecepatan aliran $6.25 \mathrm{~m} / \mathrm{s}$ atau pada $\mathrm{Re}=18.100$ dibandingkan dengan tanpa penghalang adalah $86.76 \%$.

\section{KESIMPULAN}

Dari hasil penelitian yang telah dilakukan dapat ditarik kesimpulan sebagai berikut:

1. Adanya penghalang mampu menurunkan koefisien drag.

2. Semakin besar bilangan Reynold atau semakin besar kecepatan aliran udara koefisien drag semakin kecil.

3. Pada bilangan Reynold $\operatorname{Re}=11.800, \mathrm{Re}=$ 9.170 dan $\operatorname{Re}=6.480$ koefisien drag lebih besar dibandingkan dengan tanpa penghalang.

\section{DAFTAR PUSTAKA}

[1] Chew, Y T., L S Pan, \& T S Lee.1997. Numerical Simulation of the Effect Of a Moving Wall On Separation Of Flow Past a Symmetrical Aerofoil, ImechE, 212.

[2] Fox,R.W.1985.,Introduction To Fluid Mechanics, John Wiley \& Sons, New York,

[3] Igarashi, T.1997. Drag Reduction Of a Square Prism by Flow Control Using a Small Rod, Journal of Wind Engineering and Industrial Aerodynamics, 69 - 71, 141 $-153$.
[4] Incropera, F. P. \& D. P. DeWitt. 1981. Fundamentals of Heat And Mass Transfer, John Wiley \& Sons, New York,

[5] Lee, S., S. Lee, \& C.2004. Park, Reducing The Drag On a Circular Cylinder by Upstream Installation Of a Small Control Rod, Fluid Dynamics Reseach , 34(2004): 233-250.

[6] Sutardi \& C. Y. Ching.1999. Pertumbuhan Lapis Batas Turbulen Di Belakang Sebuah Alur Melintang Yang Berpenampang Bujur Sangkar, Jurnal Teknik Mesin ITS, 26 (3): 162-168

[7] Tsutsui, T. \& T. Igarashi.2002. Drag Reduction of a Circular Cylinder in an AirStream, Journal of Wind Engineering and Industrial Aerodynamics, 90: 527-541.

[8] Yajima, Y \& O. Sano, 1996. A Note On The Drag Reduction Of a Circular Cylinder Due To Double Rows Of Holes, Fluid Dynamics Research, 18: 237 - 243.

[9] Bouak, F, and Lemay, J.1998. Passive Control of the Aerodynamics Forces Acting on a Circular Cylinder, ExperimentalThermal and Fluid Science, 16 , pp. 112-121. 